\title{
Auscultatory and phonocardiographic characteristics of supracristal ventricular septal defect
}

\author{
Odette Farrú, Gastón Duffau, and Raúl Rodríguez \\ From the Cardiac Unit, Department of Pediatrics, Roberto del Rio Hospital, \\ University of Chile and National Health Service of Chile, and the Institute of Radiology, \\ fosé foaquin Aguirre Hospital, University of Chile, Santiago, Chile
}

Six cases of supracristal ventricular septal defect, verified by right heart catheterization and left ventricular angiocardiography, are presented. Three of the 6 cases had associated aortic regurgitation both clinically and by retrograde aortography. The diagnosis was verified also by operation in 3 of the cases, and in one of these also by necropsy.

This anatomical site of the septal defect gives rise to a different picture on auscultation and by phonocardiography compared to the usual defect. A holosystolic murmur is found which is best heard in the second left intercostal space and which increases in intensity as it approaches the second sound or, alternatively, the systolic murmur is diamond-shaped with its maximum intensity shifted to the right. There is wide splitting of the second sound in expiration (mean $0.052 \mathrm{sec}$.) with pathological attenuation of $\mathbf{P 2}$.

We showed that significant lengthening of right ventricular isometric contraction and ejection periods with slight shortening of the left ventricular isometric contraction period was the cause of the pathological splitting of the second sound. A haemodynamic explanation for the splitting of the second sound, the pathological attenuation of the pulmonary component, and the unusual morphology of the systolic murmur, is attempted.

Previous studies on the auscultatory and phonocardiographic characteristics of ventricular septal defects (Craige, 1960; Leatham and Segal, 1962; Karnegis and Wang, 1963; Kahn et al., 1967) have centred on establishing a correlation between these characteristics and the size of the septal defect as well as the degree of pulmonary arteriolar resistance, but have not been particularly concerned with the topography of the defect.

The purpose of the present work is to delineate the clinical and phonocardiographic findings which we believe are characteristics of an infrequent type of ventricular septal defect, namely, one anterior to the crista supraventricularis. This anatomical position results in a unique clinical, phonocardiographic, and haemodynamic picture which distinguishes it from septal defects in the usual location.

Received 2 April 1970.

\section{Subjects and methods}

Complete clinical, electrocardiographic, radiological, phonocardiographic, and cardiac catheterization (including left ventriculography) studies were performed in 4 female and 2 male patients between the ages of 9 and 20 years. Retrograde aortography was performed additionally in 3 of them (Cases 4, 5, and 6) in whom there was associated aortic regurgitation. In 2 (Cases 2 and 3) an intracavitary phonocardiogram was also obtained. The clinical diagnosis was verified by operation in Cases 2, 3, and 6 and in one of these (Case 6) also by necropsy.

All phonocardiograms were taken on a Sanborn Twin Beam photographic recorder at a paper speed of $75 \mathrm{~mm}$. a second using a logarithmic amplifying system. The recordings were obtained from all valvular areas. An electrocardiographic lead (lead II), indirect carotid pressure pulse, and apex cardiogram from the left ventricle (Benchimol and Dimond, 1963; Benchimol, Legler, and Dimond, 1963) were used for timing.

Right heart catheterization was performed under premedication with pethidine (I mg./kg.) and promethazine $(0.5 \mathrm{mg} . / \mathrm{kg}$.). A Cournand No. 7 
catheter was advanced into the pulmonary artery through the saphenous or median basilic vein. Pressures were recorded on an Electronics for Medicine Recorder Model PR-7, using Statham P23D pressure transducers. Oxygen saturations were determined by the method of Van Slyke and Neill (I925). Cardiac output was estimated by the direct Fick method. Left ventricular and ascending aortic angiocardiograms were obtained after injection of 75 per cent Hypaque ( $1 \mathrm{ml} . / \mathrm{kg}$.) through an NIH No. 7 catheter with closed tip and multiple lateral openings, which was introduced through a femoral arteriotomy. An ElemaSchönander biplane angiocardiograph was used; 6 films were exposed per second for 3 seconds.

Left ventricular angiocardiograms were analysed with particular attention paid to the anatomical site of the shunt and the size of the shunted stream of contrast material during various phases of the cardiac cycle. The diameter of the shunted stream as it originated from the inter- ventricular septum was measured in the lateral projection of the angiocardiogram during different phases of ventricular systole. Careful attention was paid to the position of the defect in relation to the aortic root.

A jet of contrast substance passing from the - left to the right ventricle superiorly to the crista was regarded as a direct sign of a ventricular - septal defect anterior to the crista supraventricularis; less direct evidence was the presence of contrast substance filling the outflow tract and/or the pulmonary artery with poor opacification of the body of the right ventricle, but without direct visualization of the jet of contrast material.

We classified the degree of aortic regurgitation as mild, moderate, or severe, according to the degree of opacification of the left ventricle after reflux of the opaque substance following ascending aortic injection.

In all subjects, phonocardiographic measurements were made during expiration from the onset of electrical activation (QRS) to the onset of the first sound (electromechanical interval of the left ventricle) and from mitral closure (MI) to the carotid rise (corrected for delay in the system by subtracting the A2-dicrotic notch interval); these -were assumed to give an approximation of the isometric time of the left ventricle.

Measurements from the onset of the carotid rise to the dicrotic notch were used to estimate the ejection time of the left ventricle, and each measurement was compared with the ejection time of young normal subjects (Leatham and Segal, 1962).

- Other measurements included the interval from the onset of electrical activation (QRS) to the upstroke of the right ventricular (RV) pressure (electromechanical interval of the right ventricle) and to the rise of pulmonary artery pressure. Measurements from the onset of the right ventricular rise to the pulmonary artery rise reflected ' the isometric time, and from pulmonary artery Fise to the dicrotic notch, the ejection time of the right ventricle; these were also compared with the normal values given by Leatham and Segal (1962).
The delay in the system was only $0.005 \mathrm{sec}$. and no correction was made.

\section{Results}

In Cases I, 2, and 3 the supracristal ventricular septal defect was an isolated lesion, and in Cases 4, 5, and 6 it was associated with aortic regurgitation. In all 6 cases, the thrill and the systolic murmur were of maximum intensity in the second left intercostal space; the murmur was holosystolic, loud or very loud ( $5 / 6$ or $6 / 6$ degree), but increasing towards the second sound overlapping its aortic component. In 2 cases, the pulmonary component was delayed and softened; in the rest the pulmonary component could not be heard. A mitral diastolic murmur was not heard or recorded in any case. In the 3 cases with aortic regurgitation, a blowing decrescendo diastolic murmur of 2-3/6 intensity was heard and recorded in the second and third left intercostal space.

FIG. I Case 3. Isolated supracristal ventricular septal defect. Logarithmic phonocardiogram taken in expiration. Note the holosystolic murmur increasing towards the second sound both in intensity and frequency. $P_{2}$ delayed and reduced. Loudest in second left intercostal space.
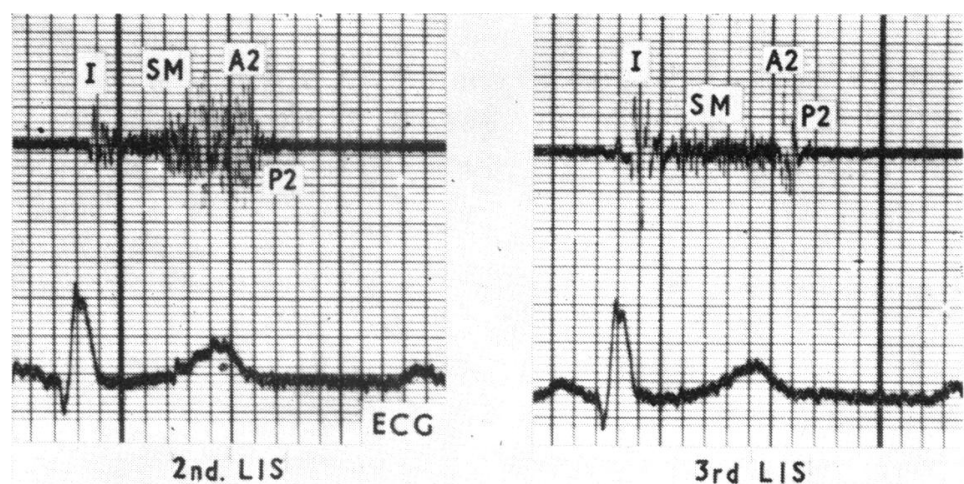

3rd LIS
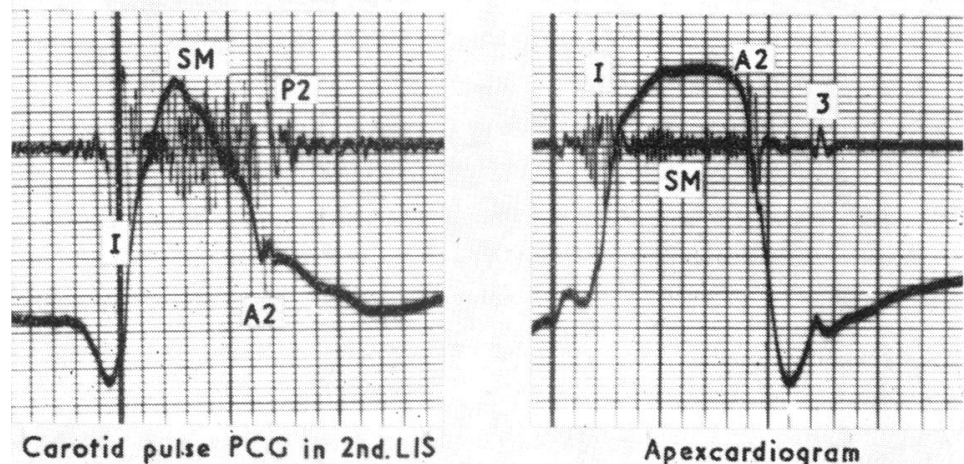

Apexcardiogram 
The phonocardiograms in all 6 patients showed similar characteristics with respect to the morphology of the systolic murmur and the behaviour of the second sound (Fig. I and 2). In all, the maximum recorded intensity of the murmur was the second intercostal space; the murmurs were holosystolic but with conspicuous late systolic accentuation or were diamond shaped with the peak shifted to the right. The terminal vibrations of the murmur covered the aortic component of the second sound. The second sound was pathologically split in expiration (between 0.04 sec. and $0.08 \mathrm{sec}$.) with an abnormally soft $\mathrm{P2}$. In the cases with associated aortic regurgitation (Fig. 2) the aortic diastolic murmur was recorded as a short decrescendo, high-frequency murmur in the second and third intercostal spaces.

To elucidate the mechanism of the wide splitting of the second sound in the 6 cases of supracristal ventricular septal defect, we measured the different components of the interval Q-A2 and Q-P2, which represent the electromechanical interval, isometric contraction, and ejection time of the right and left ventricles (Table I). The electromechanical interval of the right ventricle was normal. The isometric contraction of the right ventricle was clearly increased; on the other hand, the isometric contraction of the left ventricle was slightly decreased. The ejection time of the right ventricle was also clearly increased while the ejection time of the left ventricle was normal. The A2-P2 interval in expiration was clearly increased.

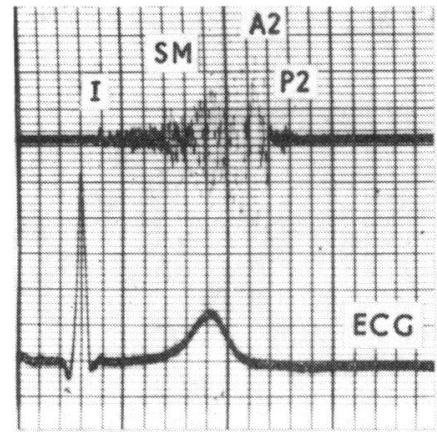

2nd. LIS Diaphragm bell

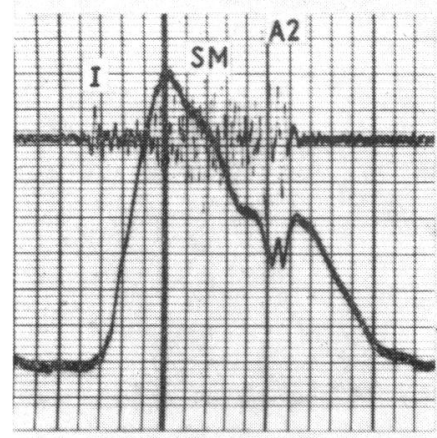

Corotid pulse PCG in 2 nd. LIS
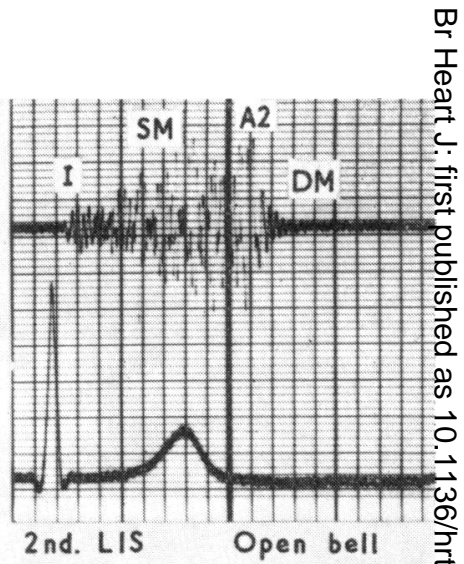

FIG. 2 Case 5. Supracristal ventricular septal defect with aortic regurgitation. In addition to the features shown in Fig. I, a protodiastolic murmur in the second left intercostal space is present.

TABLE I Measurements of different components of $Q-A 2$ and $Q-P_{2}$ interval in 6 cases of supracristal ventricular septal defect compared with normal data

\begin{tabular}{|c|c|c|}
\hline & $\begin{array}{l}\text { Normal (sec.) } \\
\text { (Leatham and Segal, 1962) }\end{array}$ & $\begin{array}{l}\text { Supracristal ventricular } \\
\text { septal defect (sec.) }\end{array}$ \\
\hline $\begin{array}{l}\text { Electromechanical interval } \\
\text { Right side }(\mathrm{Q}-\mathrm{RV}) \\
\text { Left side }\left(\mathbf{Q}-\mathbf{M}_{\mathbf{1}}\right)\end{array}$ & $\begin{array}{l}0.05 \text { mean }(0.04-0.06) \\
0.05 \text { mean }(0.04-0.06)\end{array}$ & $\begin{array}{l}0.05 \text { mean }(0.04-0.08) \\
0.05 \text { mean }(0.04-0.06)\end{array}$ \\
\hline $\begin{array}{l}\text { Isometric contraction time } \\
\text { Right side (RV-PA) } \\
\text { Left side ( }\left(M_{1} \text {-carotid rise) }\right.\end{array}$ & $\begin{array}{l}0.02 \text { mean }(0.02-0.03) \\
0.03 \text { mean }(0.03-0.04)\end{array}$ & $\begin{array}{l}0.05 \text { mean }(0.02-0.08) \\
0.02 \text { mean }(0.02-0.04)\end{array}$ \\
\hline $\begin{array}{l}\text { Ejection time } \\
\text { Right side (PA rise-dicrotic notch) }\end{array}$ & $\begin{array}{l}\text { Varied with heart rate } \\
\text { from } 0.24 \text { to } 0.30\end{array}$ & 0.033 mean $(0.32-0.38)$ \\
\hline Left side (carotid rise-dicrotic notch) & $\begin{array}{l}\text { Varied with heart rate } \\
\text { from } 0.22 \text { to } 0.30\end{array}$ & 0.26 mean $(0.24-0.28)$ \\
\hline A2-P2 interval & $0.028 \pm 0.010$ & 0.05 mean $(0.04-0.08)$ \\
\hline
\end{tabular}

Catheter delay (0.005 sec.) not subtracted. Carotid delay subtracted (A2-dicrotic notch).

$M_{1}$, first apical heart sound (first major vibrations); RV, right ventricle; PA, pulmonary artery. 
In summary, there was a clear prolongation of the isometric contraction and ejection time of the right ventricle and a slight shortening of the isometric contraction of the left ventricle.

The intracardiac phonocardiogram (Fig. 3) revealed that the holosystolic murmur was more intense in the infundibular region than in the body of the right ventricle.

FIG. 3 Case 3. Intracardiac phonocardiogram. From above downwards: electrocardiogram, phonocardiogram, pressure curve. The right ventricle and pulmonary artery pressure are normal (30/3 and $27 / 8 \mathrm{~mm} . \mathrm{Hg}$, respectively). Note that the holosystolic murmur is louder in the right ventricular outflow tract than in the right ventricular inflow tract or in the pulmonary artery trunk.

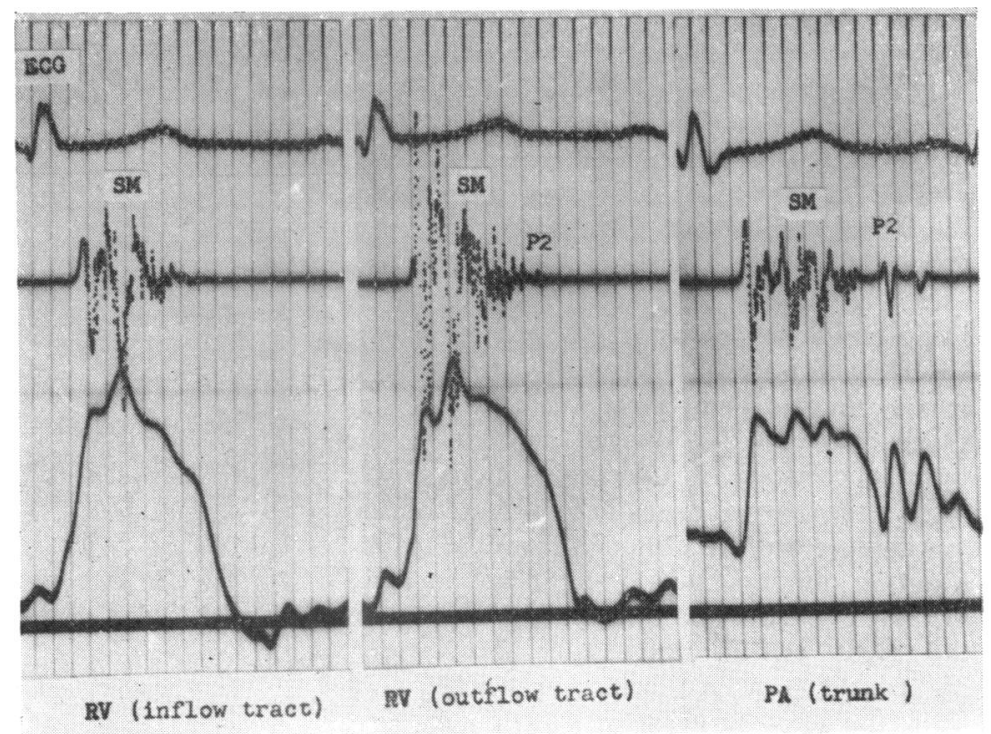

TABLE 2 Cardiac catheterization in 6 patients with supracristal ventricul ar septal defect

\begin{tabular}{|c|c|c|c|c|c|c|}
\hline \multirow[t]{2}{*}{ Case No. } & \multirow{2}{*}{$\begin{array}{l}\text { Right atrium } \\
\text { (mean } \mathrm{Pr} \text { ) }\end{array}$} & \multicolumn{2}{|c|}{ Right ventricle $(\mathrm{mm} . \mathrm{Hg})$} & \multirow{2}{*}{$\begin{array}{l}\text { Pulmonary } \\
\text { artery } \\
\text { (mm. } \mathrm{Hg} \text { ) }\end{array}$} & \multicolumn{2}{|l|}{ Femoral artery } \\
\hline & & Inflow tract & Outflow tract & & $\operatorname{Pr}(m m . H g)$ & $\mathrm{O}_{2}<$ sat. \\
\hline $\begin{array}{l}1 \\
2 \\
3 \\
4 \\
5 \\
6\end{array}$ & $\begin{array}{l}(0) \\
(3) \\
(4) \\
(4) \\
(1) \\
(4)\end{array}$ & $\begin{array}{l}24 / 5 \\
28 / 5 \\
30 / 3 \\
25 / 3 \\
36 / 2 \\
40 / 4\end{array}$ & $\begin{array}{l}24 / 5 \\
28 / 5 \\
30 / 4 \\
25 / 3 \\
36 / 2 \\
40 / 4\end{array}$ & $\begin{array}{l}22 / 9 \\
23 / 8 \\
27 / 8 \\
20 / 10 \\
29 / 11 \\
40 / 15\end{array}$ & $\begin{array}{r}115 / 65 \\
90 / 60 \\
90 / 50 \\
90 / 60 \\
105 / 50 \\
140 / 70\end{array}$ & $\begin{array}{l}92 \\
97 \\
97 \\
93 \\
97 \\
90\end{array}$ \\
\hline
\end{tabular}

TABLE 3 Cardiac catheterization (oxygen content) and angiocardiographic data in 6 patients with supracristal ventricular septal defect

\begin{tabular}{|c|c|c|c|c|c|c|c|}
\hline \multirow{2}{*}{$\begin{array}{l}\text { Case } \\
\text { No. }\end{array}$} & \multirow{2}{*}{$\begin{array}{l}\text { Right } \\
\text { atrium } \\
\mathrm{O}_{2} \text { vol. } \\
\text { per cent }\end{array}$} & \multicolumn{2}{|c|}{ Right ventricle } & \multirow{2}{*}{$\begin{array}{l}\text { Pulmonary } \\
\text { artery } \\
\mathrm{O}_{2} \text { vol. } \\
\text { per cent }\end{array}$} & \multirow[t]{2}{*}{$Q P / Q S$} & \multirow[t]{2}{*}{ Left ventriculography } & \multirow[t]{2}{*}{ Aortography } \\
\hline & & $\begin{array}{l}\text { Inflow tract } \\
\mathrm{O}_{2} \text { vol. } \\
\text { per cent }\end{array}$ & $\begin{array}{l}\text { Outflow tract } \\
\mathrm{O}_{2} \text { vol. } \\
\text { per cent }\end{array}$ & & & & \\
\hline $\mathbf{I}$ & $10 \cdot 78$ & II 139 & $12 \cdot 00$ & 12.86 & $1 \cdot 39$ & $\begin{array}{l}\text { Supracristal ventricular } \\
\text { septal defect } 4-5 \mathrm{~mm} \text {. }\end{array}$ & - \\
\hline 2 & 13.00 & 14.40 & 14.50 & $14 \cdot 70$ & $2 \cdot 00$ & $\begin{array}{l}\text { Small supracristal } \\
\text { ventricular septal } \\
\text { defect (indirect sign) }\end{array}$ & 一 \\
\hline 3 & 13.25 & 13.25 & $14 \cdot 00$ & 14.50 & $1 \cdot 76$ & $\begin{array}{l}\text { Small supracristal } \\
\text { ventricular septal } \\
\text { defect (indirect sign) }\end{array}$ & - \\
\hline 4 & 10.94 & II'3I & - & $11 \cdot 59$ & $I \cdot 26$ & $\begin{array}{l}\text { Supracristal ventricular } \\
\text { septal defect } 3-4 \mathrm{~mm} \text {. }\end{array}$ & $\begin{array}{l}\text { Aortic regurg. grade I } \\
\text { (posterior cusp); } \\
\text { bicuspid valve }\end{array}$ \\
\hline 5 & II $\cdot 77$ & $12 \cdot 38$ & $13 \cdot 17$ & 13.50 & $1 \cdot 84$ & $\begin{array}{l}\text { Moderate supracristal } \\
\text { ventricular septal } \\
\text { defect (indirect sign) }\end{array}$ & $\begin{array}{l}\text { Aortic regurg. grade } 3 \\
\text { (anterior cusp); } \\
\text { bicuspid valve }\end{array}$ \\
\hline 6 & 13.80 & $14: 40$ & 15.40 & 15.00 & $I \cdot 44$ & $\begin{array}{l}\text { Moderate supracristal } \\
\text { ventricular septal } \\
\text { defect (indirect sign) }\end{array}$ & $\begin{array}{l}\text { Aortic regurg. grade } 3 \\
\text { (posterior cusp); } \\
\text { tricuspid valve }\end{array}$ \\
\hline
\end{tabular}


The electrocardiographic and radiological findings were typical of any ventricular septal defect of moderate size. All the patients were in functional class I or II.

Cardiac catheterization (Table 2) revealed normal findings in all. The oxygen content of the blood samples from the different chambers (Table 3) was of interest; a significant increase in the oxygen content was seen in the infundibular region and not in the body of the right ventricle in 4 cases (Cases $1,3,5$, and 6); in 2 of them there was a further significant increase in oxygen content in the pulmonary artery; in Case 2 this increase was seen in the body of the right ventricle; in Case 4, a sample was not obtained from the infundibulum nor was there a significant increase in the oxygen content of the samples between the right atrium and pulmonary artery, but the left-side ventriculography (Fig. 4A) showed a small supracristal ventricular septal defect. In no case was the pulmonary flow more than twice the systemic flow.

The angiocardiograms showed a high ventricular septal defect (supracristal) (Fig. 4 and 5), with early filling of the infundibulum and/or pulmonary artery and little or no contrast in the body of the right ventricle. In general, the ventricular septal defect was small or medium in size. In Cases $I$ and 4 it was possible to distinguish the jet of contrast passing from left to right ventricle anterior to the crista supraventricularis. In the other cases, the angiocardiographic sign of an anterior ventricular septal defect was indirect. In Cases I and 4, showing a jet high in the right ventricular cavity, the size of the defect diminished in systole and increased in diastole (Fig. 4). The contrast substance was observed to enter the pulmonary artery not only in systole but also in early diastole when the aortic valves were already closed.

Aortography in 2 of the 3 cases with aortic regurgitation (Cases 4 and 5) showed a bicuspid valve. The regurgitation was minimal in Case 4 and maximal in Cases 5 and 6.

\section{Discussion}

Supracristal ventricular septal defect occurs in 8 per cent of isolated ventricular septal defect (Karnegis and Wang, 1963; Keith, Rowe, and Vlad, 1967; Becu et al., 1956; Chuaqui, 1968). This type of defect produces a clinical and haemodynamic picture distinct from the well-known one of classic ventricular septal defect. Clinically, a thrill is present with a systolic murmur loudest in the second intercostal space, increasing in inten-
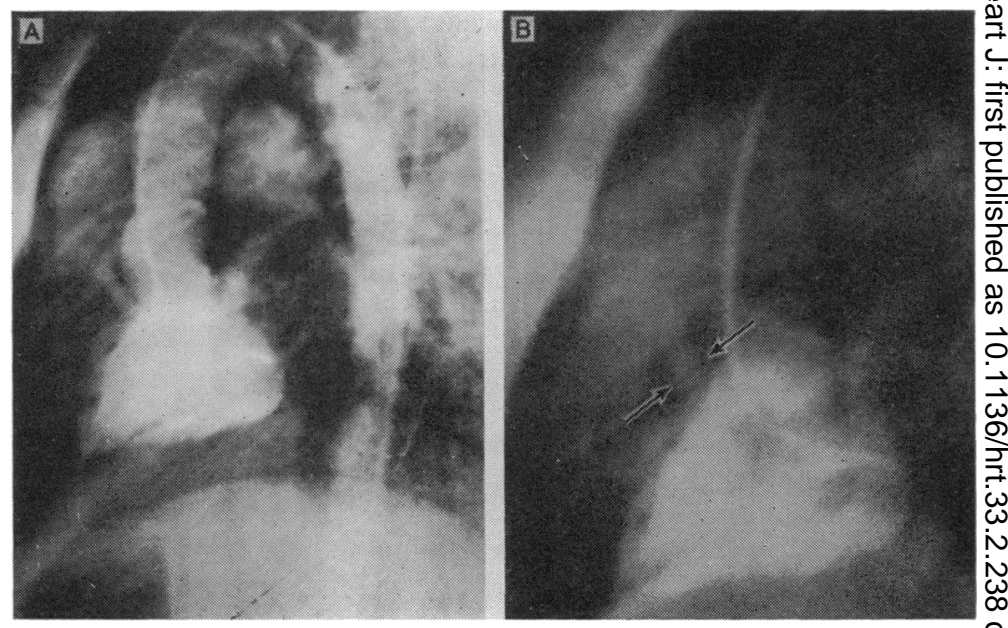

FIG. 4 Case I. Isolated supracristal ven-

tricular septal defect. Left ventriculography.

(A) Systole. (B) Protodiastole. Note the jet of

contrast substance passing from the left to the

right ventricular infundibulum, with early

filling of the pulmonary artery and poor

opacification of the right ventricular body.

Note also the variation in size of the defect

both in systole and diastole.

FIG. 5 Case 4. Supracristal ventricular septal defect with aortic regurgitation. $(A)$

Left ventriculography: direct sign of supracristal ventricular septal defect. (B) Aortography: aortic regurgitation (posterior cusp).
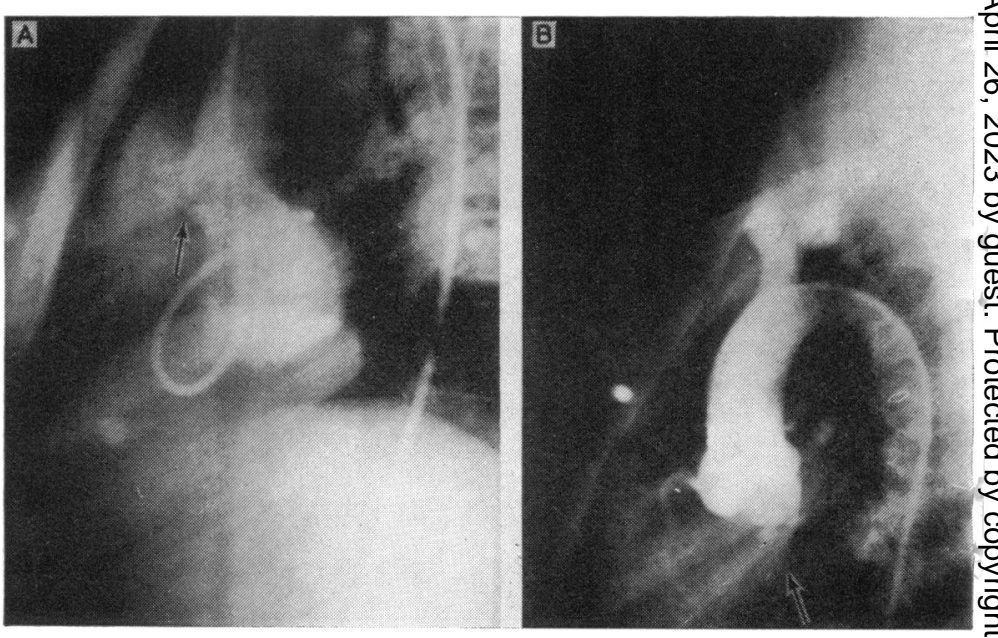
sity towards the second sound with a diminished pulmonary component of the second sound. The picture may initially suggest the diagnosis of severe pulmonary stenosis before one examines the chest $x$-ray and the electrocardiogram. If conspicuous aortic regurgitation is associated with a supracristal ventricular septal defect, the presence of a to-and-fro murmur loudest in the second intercostal space may lead erroneously to the diagnosis of a persistent ductus (Gross, 1952; Plauth $e t$ al., 1965) as happened in one of our patients (Case 5).

There are few descriptions of the clinical picture produced by a supracristal ventricular septal defect (Kahn et al., 1967; Reynolds, 1966; Walker et al., 1965). In all previous studies, reference to the auscultatory findings is limited to its occurrence in the second left intercostal space; no reference is made to the other characteristics of the murmur which we have described above or to the behaviour of the second sound.

Our cases illustrate three important phonocardiographic findings of a supracristal ventricular septal defect. These are: (I) a patho-

- logical splitting of the second sound in expiration, (2) a pathological attenuation of the pulmonary component, and (3) the existence of a holosystolic murmur with maximum intensity near the second sound or diamond shaped with its peak shifted to the right, overlapping A2. In the case of supracristal ventricular septal defect published by Reynolds (I966), one can see a pathological splitting of the second sound in the left intercostal space with a diminished $\mathrm{P}_{2}$ lessened in the phonocardiogram, though these points are not mentioned in the text.

Leatham and Segal (1962) noted that the ordinary ventricular septal defect with small - to moderate flow produces pathological splitting of the second sound in expiration (between 0.03 sec. and 0.075 sec.) and attributed this to a slight diminution of the isometric contraction period of the left ventricle and an important lengthening of the electromechanical interval of the right ven- tricle; as a result, there is corresponding early aortic closure and late pulmonary closure.

- They interpreted the reduction of the isometric contraction period of the left ventricle as due to diastolic overloading of the left ventricle unaccompanied by a similar overloading of the right ventricle that would balance this veffect. They were unable to give a satisfactory explanation for the lengthening of the electromechanical interval of the right ventricle. In our cases, the pathological splitting was due in part to the slight shortening of the isometric contraction period of the left ventricle with subsequent early aortic closing as described by Leatham and Segal. However, the main cause was a delay in pulmonary valve closure due to a lengthening of the isometric contraction and ejection period of the right ventricle. The mechanism is somewhat analogous to that observed in pulmonary valve stenosis. We believe the most likely explanation is overloading of the infundibulum during systole produced by the left-to-right shunt at this level which acts as an obstruction to right ventricular contraction and interferes with its emptying; consequently, the systolic ejection period of the right ventricle is lengthened.

Leatham and Segal (1962) state that in ventricular septal defect with a small or moderate flow, the pulmonary component is of normal loudness. The pathological attenuation of $\mathrm{P}_{2}$ in our cases of supracristal ventricular septal defect may be explained by pulmonary valve closure occurring when the infundibulum is still contracting because of the lengthening of right ventricular systole. As a result, the differential pressure between the pulmonary artery and right ventricle would be diminished in this moment and therefore pulmonary closing pressure would be small.

We noted peculiar behaviour of the systolic murmur. In spite of being holosystolic, it increased towards the second sound or was diamond shaped with a late peak. This may be related to our observation that the defect gets smaller in late systole because of the late contraction of the infundibulum. The higher frequency of the murmur towards the end of systole lends support to this concept.

The angiocardiograms showed that the contrast material continued to fill the pulmonary artery during the early protodiastolic period because of lengthening of right ventricular systole. This explains the observation that the systolic murmur overlaps the aortic component of the second sound.

The phonocardiographic differentiation between supracristal ventricular septal defect and pulmonary valve stenosis is difficult. There are certain distinguishing features, however. With supracristal ventricular septal defect, the systolic murmur begins with the first sound and increases in intensity towards the second sound. If this were due to pulmonary stenosis, the lesion would have to be severe, the splitting of the second sound should be wider, and the pulmonary component far more attenuated than we observed in our cases of ventricular septal defect.

The cardiac catheterization data may also lead to confusion in diagnosis, unless one is careful. If no blood samples are taken 
immediately below the pulmonary valve, the left-to-right shunt may be erroneously interpreted as arising in the pulmonary artery, since the low right ventricular samples may not reflect the shunt. Additional diagnostic confusion may arise if one is unaware that the shunt from the left ventricle does not produce typical filling of the body of the right ventricle: the contrast substance can pass in a diagonal direction directly into the infundibulum or even into the pulmonary artery.

The combination of ventricular septal defect and aortic regurgitation is described in 3.3 to 6.6 per cent of all cases of ventricular septal defect (Keith et al., 1967; Plauth et al., 1965; Nadas, 1963; Gasul, Arcilla, and Lev, I966; Wood, 1956). The aortic insufficiency is acquired, though it is predisposed by the characteristics of the ventricular septal defect, which makes the prolapse of one or two of the aortic valve cusps possible (Sakakibara and Konno, I962, 1968). This complication is not restricted to large ventricular septal defects. The most important factor is its anatomical site and not its size (Ainger and Pate, 1963; Nadas et al., 1964). The syndrome is produced when the ventricular septal defect is subaortic (either inferior or superior to the crista supraventricularis), that is, when it does not have a superior border so that the aortic valve loses its support. Prolapse of the valve eventually occurs as a result of the haemodynamic disturbance associated with the ventricular septal defect, the left-to-right shunt over a period of time tending to dislocate the aortic leaflets (Gialloreto and Loiselle, I963; Halloran, Talner, and Browne, 1965). Though aortic insufficiency in this sense is acquired, it clearly has an anatomical basis in the congenital malformation which involves lack of support to the aortic valves (Sakakibara and Konno, 1962; Nadas et al., 1964; Halloran et al., 1965).

In our 3 cases of ventricular septal defect with aortic regurgitation, the systolic murmur was detected within the first year of life; on the other hand, the diastolic murmur of aortic regurgitation was heard at 7 years of age in Case 4, at 6 years in Case 5, and at 17 years of age in Case 6. This supports Nadas (1963) who states that the aortic regurgitation is acquired though conditioned by congenital factors.

According to Van Praagh and McNamara (1968), the supracristal ventricular septal defect associated with aortic regurgitation has basically normal aortic valves and not bicuspid valves. In our patients, however, 2 of the 3 cases (Cases 4 and 5) had bicuspid aortic valves.
The association of aortic regurgitation with supracristal ventricular septal defect does not modify the phonocardiographic picture that we believe is characteristic of this type of septal defect.

\section{References}

Ainger, L. E., and Pate, J. W. (1963). Rupture of a sinus of Valsalva aneurysm in an infant. Surgical correction. American fournal of Cardiology, II, 547.

Becu, L. M., Fontane, R. S., DuShane, J. W., Kirklin, J. W., Burchell, H. B., and Edwards, J. E. (1956). Anatomic and pathologic studies in ventricular septal defect. Circulation, 14, 349.

Benchimol, A., and Dimond, E. G. (1963). The normal and abnormal apexcardiogram. American fournal of Cardiology, 12, 368.

_, Legler, J. F., and Dimond, E. G. (1963). The carotid tracing and apexcardiogram in subaortic stenosis and idiopathic myocardial hypertrophy. American fournal of Cardiology, 11, 427.

Chuaqui, B. (1968). Caracteres morfológicos de las comunicaciones interventriculares que rebasan el músculo papilar del cono. I Jornadas Científicas. Facultad de Medicina, Universidad Católica de Chile. 16 de Septiembre. Santiago.

Craige, E. (1960). Phonocardiography in interventricular septal defects. American Heart fournal, 60, 51.

Gasul, B. M., Arcilla, R. A., and Lev, M. (1966). Heart Disease in Children. Diagnosis and Treatment, p. 276. J. B. Lippincott, Philadelphia.

Gialloreto, O. P., and Loiselle, G. (1963). Aneurysm of aortic sinus of Valsalva associated with high ventricular septal defect. American fournal of Cardiology, II, 537.

Gross, R. E. (1952). The patent ductus arteriosus. Observations on diagnosis and therapy in 525 surgically treated cases. American fournal of Medicine, 12, 472.

Halloran, K. H., Talner, N. S., and Browne, M. J. (1965). A study of ventricular septal defect associated with aortic insufficiency. American Heart fournal, 69, 320.

Kahn, D. R., Vathayanon, S., Stern, A. M., Ferguson, P. W., and Sloan, H. (1967). Location of ventricular septal defects. Circulation, 36, Suppl. 2, p. 153.

Karnegis, J. N. and Wang, Y. (1963). The Q-I interval of the phonocardiogram in patients with ventricular septal defect, patent ductus arteriosus and Blalock anastomosis. American fournal of Cardiology, II, 452.

Keith, J. D., Rowe, R. D., and Vlad, P. (1967). Heart Disease in Infancy and Childhood, 2nd ed., pp. 296-372. The Macmillan Company, New York, and Collier-Macmillan, London.

Leatham, A., and Segal, B. (1962). Auscultatory and phonocardiographic signs of ventricular septal defect with left-to-right shunt. Circulation, 25, 318.

Nadas, A. S. (1963). Pediatric Cardiology, 2nd ed., p. 434. W. B. Saunders, Philadelphia and London. , Thilenius, O. G., LaFarge, C. G., and Hauck, A. J. (1964). Ventricular septal defect with aortic regurgitation. Medical and pathologic aspects. Circulation, 29, 862.

Plauth, W. H., Jr., Braunwald, E., Rockoff, S. D., Mason, D. T., and Morrow, A. G. (1965). Ventricular septal defect and aortic regurgitation. Clinical, haemodynamic and surgical considerations. American fournal of Medicine, 39, 552. 
Reynolds, J. L. (I966). Supracristal ventricular septal defect. American fournal of Cardiology, 18, 610.

Sakakibara, S., and Konno, S. (1962). Congenital aneurysm of the sinus of Valsalva. Anatomy and classification. American Heart fournal, 63, 405. , and- (1968). Congenital aneurysm of the sinus of Valsalva associated with ventricular septal defect. Anatomical aspects. American Heart fournal, 75, 595 .

Van Praagh, R., and McNamara, J. J. (1968). Anatomic types of ventricular septal defect with aortic insufficiency. Diagnostic and surgical considerations. American Heart fournal, 75, 604.
Van Slyke, D. D., and Neill, J. M. (1925). The determination of gases in blood and other solutions by vacuum extraction and manometric measurement. Fournal of Biological Chemistry, 61, 523.

Walker, W. J., Garcia-Gonzalez, E., Hall, R. J., Czarnecki, S. W., Franklin, R. B., Das, S. K., and Cheitlin, M. D. (1965). Interventricular septal defect. Analysis of 415 catheterized cases, ninety with serial hemodynamic studies. Circulation, 31, 54.

Wood, P. (1956). Diseases of the Heart and Circulation, 2nd ed., p. 378. Eyre and Spottiswoode, London. 